\title{
Circuit-Specific Intracortical Hyperconnectivity in Mice with Deletion of the Autism-Associated Met Receptor Tyrosine Kinase
}

\author{
Shenfeng Qiu, ${ }^{1 *}$ Charles T. Anderson, ${ }^{2 *}$ Pat Levitt, ${ }^{1}$ and Gordon M. G. Shepherd ${ }^{2}$ \\ ${ }^{1}$ Zilkha Neurogenetics Institute, Department of Cell and Neurobiology, Keck School of Medicine, University of Southern California, Los Angeles, California \\ 90089, and 2Department of Physiology, Feinberg School of Medicine, Northwestern University, Chicago, Illinois 60611
}

Local hyperconnectivity in the neocortex is a hypothesized pathophysiological state in autism spectrum disorder (ASD). MET, a receptor tyrosine kinase that regulates dendrite and spine morphogenesis, has been established as a risk gene for ASD. Here, we analyzed the synaptic circuit organization of identified pyramidal neurons in the anterior frontal cortex of mice with a dorsal pallium-derived, conditional knock-out (cKO) of Met. Synaptic mapping by glutamate uncaging identified layer 2/3 as the main source of local excitatory input to layer 5 projection neurons in controls. In both $\mathrm{cKO}$ and heterozygotes, this pathway was stronger by a factor of $\sim 2$. This increase was both sublayer and projection-class specific, restricted to corticostriatal neurons in upper layer $5 \mathrm{~B}$ and not neighboring corticopontine neurons. Paired recordings in cKO slices demonstrated increased unitary connectivity. We propose that excitatory hyperconnectivity in specific neocortical microcircuits constitutes a physiological basis for Met-mediated ASD risk.

\section{Introduction}

Genetic factors play an important role in the etiology of autism spectrum disorder (ASD). Accumulating evidence supports an association of disrupted MET receptor tyrosine kinase-mediated signaling and ASD risk. MET is a pleiotropic factor in the ontogenesis of multiple organs and a key signaling component in a number of neurodevelopmental events (Bronner-Fraser, 1995; Maina et al., 1998; Gutierrez et al., 2004; Judson et al., 2010). We first described the relevance of human MET gene (Mendelian Inheritance in Man 164860) to ASD by reporting that a functional single-nucleotide polymorphism (SNP) in the MET promoter region confers genetic risk for ASD (Campbell et al., 2006). This and other ASD-associated promoter variants and copy number variants (Campbell et al., 2009; Jackson et al., 2009; Sousa et al., 2009; Thanseem et al., 2010) and the observed reduction in MET protein in postmortem neocortex from ASD subjects (Campbell et al., 2007) have since been substantiated in multiple additional cohort studies.

\footnotetext{
Received Dec. 16, 2010; revised Feb. 4, 2011; accepted Feb. 17, 2011.

Author contributions: S.Q., C.T.A., P.L., and G.M.G.S. designed research; S.Q. and C.T.A. performed research; S.Q and C.T.A. analyzed data; S.Q., C.T.A., P.L., and G.M.G.S. wrote the paper.

This work was supported by a Simons Foundation Autism Research Initiative grant (P.L., G.M.G.S.) and by National Institutes of Health Grants T32NS041234 (C.T.A.), K99MH087628 (S.Q.), R01MH067842 (P.L.), and R01NS061963 (G.S.). We thank Patrick Sheets for help and advice with LSPS experiments, Lisa Topolnik for advice on labeling and imaging, and Luke Trapp for two-photon imaging. We are grateful to Mac Hooks, Whit Tao, Barb Thompson, and Li Zhang for comments on this manuscript.

*S.Q. and C.T.A. contributed equally to this work.

Correspondence should be addressed to either of the following: Dr. Gordon M. G. Shepherd, Morton 5-660, 303 East Chicago Avenue, Chicago, IL 60611, E-mail: g-shepherd@northwestern.edu; or Dr. Pat Levitt, Department of Cell and Neurobiology, Keck School of Medicine, University of Southern California, 1501 San Pablo Street, Los Angeles, CA 90089, E-mail: plevitt@usc.edu.

DOI:10.1523/JNEUROSCI.6569-10.2011

Copyright $\odot 2011$ the authors $\quad 0270-6474 / 11 / 315855-10 \$ 15.00 / 0$
}

We recently investigated neurodevelopmental features of Met function in the context of forebrain circuitry related to ASD etiology. Met is expressed transiently in the postnatal mouse forebrain, particularly cortical, amygdala, and hippocampal projection neurons, with a peak during the second postnatal week (Judson et al., 2009), when rates of dendritogenesis and synaptogenesis are maximal (Blue and Parnavelas, 1983; Micheva and Beaulieu, 1996). Additionally, in a conditional mutant (Met-cKO) of the mouse dorsal pallium, generated by crossing a "floxed" Met line with an $E m \times 1^{\text {cre }}$ driver line (Gorski et al., 2002; Judson et al., 2009, 2010), neocortical neuron architecture is altered. Specifically, the proximal dendritic arbors are increased, and distal arbors are reduced (Judson et al., 2010). In addition, spine volume is increased by $20 \%$. These morphological changes suggest a potential substrate for cortical circuit dysfunction in the Met-cKO mice.

It has been hypothesized, based on functional imaging studies in ASD, that cortical dysfunction arises both from long-range "underconnectivity" between cortical areas and from short-range "overconnectivity" within areas, especially in frontal and temporal cortex (Frith, 2004; Just et al., 2004; Courchesne and Pierce, 2005; Geschwind and Levitt, 2007; Just et al., 2007; Scott-Van Zeeland et al., 2010). However, a neural correlate for this altered connectivity, such as synaptic "hyperconnectivity" or other functional changes in local circuits, has not been identified in human cortex. Given the role of MET in the genetic architecture of ASD risk and in regulating synapse-related neuronal structures, we investigated the functional implications of disrupted Met signaling on cortical circuit organization using Met-cKO mice. We focused on characterizing excitatory synaptic inputs to major types (corticostriatal and corticopontine) of cortical output neurons in the anterior frontal cortex (AFC) and surveyed the local circuits with synaptic mapping methods. We found that dis- 
rupted Met signaling that resulted in structural changes also generated robust pathophysiological correlates that may be relevant for understanding the etiology of ASD.

\section{Materials and Methods}

Mice were bred in-house by mating one parent homozygous for a Met allele in which exon 16 is flanked by loxP (floxed) sites $\left[\mathrm{Met}^{\mathrm{fx} / \mathrm{fx}}\right.$, provided by S. Thorgeirsson, National Cancer Institute, Bethesda, MD (Judson et al., 2009)] with another parent carrying an Emx1-cre transgene [provided by K. Jones University of Colorado, Boulder, Boulder, CO (Gorski et al., 2002)] and a single floxed Met allele $\left(\mathrm{Met}^{\mathrm{fx} /+} / E m \times l^{\mathrm{cre}}\right)$. The $M e t^{\mathrm{fx} / \mathrm{fx}}$ and $\mathrm{Met}^{\mathrm{fx} /+} / E m \times 1^{\text {cre }}$ breeding lines were both fully backcrossed onto the $\mathrm{C} 57 \mathrm{BL} / 6^{\mathrm{J}}$ background. The genotypes of their offspring (i.e., $\left.M e t^{\mathrm{fx} / \mathrm{fx}} / E m x 1^{\mathrm{cre}}, \mathrm{Met}^{\mathrm{fx} /+} / E m x 1^{\mathrm{cre}}, \mathrm{Met}^{\mathrm{fx} / \mathrm{fx}} / \mathrm{WT} ; \mathrm{Met}^{\mathrm{fx} /+} / \mathrm{WT}\right)$ were determined by PCR as described previously (Judson et al., 2009) or by real-time PCR by Transnetyx. Electrophysiological data collected at different institutions were consistent with each other. Data from male and female mice were pooled, as initial analysis of data from individual animals did not reveal any sex differences. All procedures using mice were approved by the Institutional Animal Care and Use Committee of the University of Southern California, Vanderbilt University, or Northwestern University and conformed to National Institutes of Health guidelines.

Retrograde labeling was performed in anesthetized mice as described previously (Anderson et al., 2010). Contralaterally projecting corticostriatal neurons in AFC were selectively labeled by stereotaxically injecting $\sim 50 \mathrm{nl}$ of red or green fluorescent microspheres (Lumafluor) into the (left) dorsolateral striatum (coordinates, relative to bregma: $0.0 \mathrm{~mm}$ posterior, $2.0 \mathrm{~mm}$ lateral, $2.5 \mathrm{~mm}$ ventral). Corticopontine neurons were labeled by injecting the (right) ventral pons in the region of the pontine nuclei, approached at a $50^{\circ}$ angle off the vertical axis through a craniotomy $3.2 \mathrm{~mm}$ posterior to lambda, $0.5 \mathrm{~mm}$ lateral, and $4.9 \mathrm{~mm}$ ventral from the surface of the brain. In all cases, animals received injections $\geq 16 \mathrm{~h}$ before brain slice preparation.

Brain slices were prepared as described previously (Anderson et al., 2010). Mice (male or female) were killed at postnatal day 21 (P21) to P32 by decapitation under deep isoflurane anesthesia. Brains were dissected and sectioned in ice-cold, carbogenated choline solution (in mM: 110 choline chloride, $25 \mathrm{NaHCO}_{3}, 2.5 \mathrm{KCl}, 1.25 \mathrm{NaH}_{2} \mathrm{PO}_{4}, 0.5 \mathrm{CaCl}_{2}, 7$ $\mathrm{MgSO}_{4}, 25$ D-glucose, 11.6 sodium ascorbate, and 3.1 sodium pyruvate). Parasagittal slices ( $300 \mu \mathrm{m}$ thick) of the right cerebral hemisphere containing the AFC were cut, $\sim 1-2 \mathrm{~mm}$ lateral to the midline, using a slice angle that was rolled rightward $\sim 15^{\circ}$ to align the slice plane optimally with pyramidal neuron apical dendrites and descending axons. This angle yielded two to three contiguous slices suitable for recording. We routinely verified that the recorded neurons had intact apical dendrites, based on epifluorescence visualization of the dye-filled neuron after recording. Slices were transferred to and incubated in carbogenated artificial CSF (ACSF; in mM: $126 \mathrm{NaCl}, 2.5$ $\mathrm{KCl}, 26 \mathrm{NaHCO}_{3}, 2 \mathrm{CaCl}_{2}, 2 \mathrm{MgCl}_{2}, 1.25 \mathrm{NaH}_{2} \mathrm{PO}_{4}$, and $10 \mathrm{D}$-glucose) for 30 $\mathrm{min}$ at $35^{\circ} \mathrm{C}$ and maintained at $22^{\circ} \mathrm{C}$ until recording.

Electrophysiological recordings and laser-scanning photostimulation (LSPS) mapping were performed as described previously (Anderson et al., 2010; Shepherd, 2011), with the experimenter blind to genotype. Slices were transferred to the recording chamber of a custom-built LSPS microscope, and fluorescently labeled neurons were patched with an internal solution (in mm: $126 \mathrm{~K}$-gluconate, $4 \mathrm{KCl}, 10 \mathrm{HEPES}, 4 \mathrm{ATP}, 0.3$ GTP, $10 \mathrm{~mm}$ phosphocreatine, and either 0 or 0.05 Alexa 594, 488, or 350). LSPS mapping was performed at $22^{\circ} \mathrm{C}$ in ACSF with $0.2 \mathrm{~mm}$ 4-methoxy-7-nitroindolinyl-caged glutamate (Tocris), $4 \mathrm{~mm} \mathrm{CaCl}_{2}, 4$ $\mathrm{mM} \mathrm{MgCl}_{2}$, and $5 \mu \mathrm{M} \mathrm{CPP}$ (Tocris). Intrinsic properties were measured in current-clamp mode immediately before mapping, by presenting families of current steps ( -100 to $+500 \mathrm{pA}$ in $50 \mathrm{pA}$ increments; duration, $0.5 \mathrm{~s}$ ). Traces were analyzed off-line to identify action potentials (APs). Frequency-current relationships were calculated based on the numbers of APs per current step, and the frequency-current slopes were calculated by linear regression. Spike-frequency adaptation was calculated by averaging the ratio of the third and fifth interspike interval for all responses with more than five APs. Signals were filtered at $2-4 \mathrm{kHz}$ and sampled at $10 \mathrm{kHz}$. For LSPS, we used Ephus software to control data acquisition [www.ephus.org (Suter et al., 2010)] and custom routines for off-line analysis. In some cases, neurons were filled with biocytin during recording, subsequently stained with streptavidin-conjugated fluorophores, and imaged on a two-photon laser-scanning microscope system. Paired recordings were made in plain ACSF at $32^{\circ} \mathrm{C}$.

Morphometric measurements were made from slice images captured during experiments. Cortical thickness $\left(d_{\text {cortex }}\right)$ was measured as the distance from the cortical surface (pia) to the border of layer 6 and white matter. The depth of the soma in the cortex was measured as the distance from the pia to the soma $\left(d_{\text {soma }}\right)$, and the normalized soma position was calculated as $d_{\text {soma }} / d_{\text {cortex }}$. Similarly, we measured the distance from the pia to the layer $5 \mathrm{~A} / \mathrm{B}$ border $\left(d_{5 \mathrm{~A} / \mathrm{B}}\right)$ and calculated the normalized distance as $d_{\mathrm{L} 5 \mathrm{~A} / \mathrm{B}} / d_{\text {cortex }}$. Identification of this border was guided by a previous quantification of the laminar profile of optical density in video micrographs of agranular cortex (Weiler et al., 2008). Neuronal density was measured in 50- $\mu \mathrm{m}$-thick Nissl-stained slices of AFC by counting the number of neurons in a defined region of interest in layer $2 / 3(\mathrm{a} 0.1 \times 0.2 \mathrm{~mm}$ box).

Synaptic input maps were analyzed using custom routines and published approaches (Anderson et al., 2010). These are described further in Results. We note here that black pixels in input maps, representing dendritic stimulation, are ignored in calculating averages (i.e., averages across map planes, for calculating "front views," or averages across map rows, for calculating "side views"). There are fewer black pixels in front view average maps than in individual maps, in which black pixels occur at various locations. On the one hand, this is a positive effect: more details (pixels) emerge as more neurons are pooled for averaging. On the other hand, it introduces an undersampling effect, because for these emergent pixels, the number of neurons contributing to their average pixel will be less than the total number of neurons in the group. This effect is strongest near the soma, where one or more pixels usually remain black even after averaging, but also affects pixels around the apical dendrite. The latter is potentially problematic because this is also a region of synaptic input from layer $2 / 3$. However, because black pixels tended to be sparse and variable in location, this effect was generally minor. For layer $2 / 3$ pixels, in the most severe case, the fraction of neurons contributing to the average, relative to total neurons, was 0.3 , but, on average, this fraction was $\sim 0.9$. We emphasize that average maps are used as a graphical tool to aid in the visualization of these complex three-dimensional data sets.

Unless indicated otherwise, group data including bars in graphs represent the mean \pm SEM. Differences in the means of two or more groups were tested by the Student's $t$ test (for normally distributed data) or Wilcoxon rank-sum test (for non-normally distributed data), as indicated. For all comparisons, significance was defined as $p<0.05$.

\section{Results}

\section{Electrophysiological characterization of corticostriatal neurons in AFC brain slices}

We focused on the AFC for this study because it is an area of high Met expression in the mouse (Judson et al., 2009), it is the thickest region of the mouse neocortex, and it is implicated in higherorder cognitive and motor functions, including aspects of motivated behavior. The AFC (Fig. 1) is located at the rostral pole of the neocortex just anterior to the rostral forelimb area of motor cortex (Tennant et al., 2010). It is distinct from rodent prefrontal cortex, which is situated medially and is much thinner and cytoarchitectonically simpler (Van De Werd et al., 2010) compared with the lateral agranular neocortex containing the AFC and somatic motor cortex located on the dorsolateral aspect of the frontal lobe (Caviness, 1975; Shepherd, 2009). In choosing a cortical cell type to focus on, we reasoned that layer 5 pyramidal neurons projecting to the contralateral striatum (intratelencephalic-type, "crossed" corticostriatal neurons) were particularly likely to be affected by deletion of Met. These neurons are among the subtypes of cortical neurons that express Met during the peak period of synapse formation (Judson et al., 2009), exhibit modest dendritic and spine changes, and are implicated in the cell-nonautonomous structural changes of striatal medium spiny neurons in Met-cKO (Judson et al., 2010). However, in contrast 
A

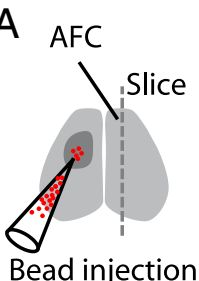
into striatum

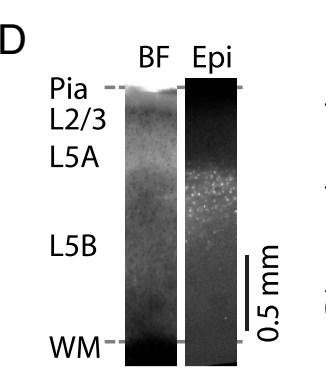

E


Intensity (norm.)
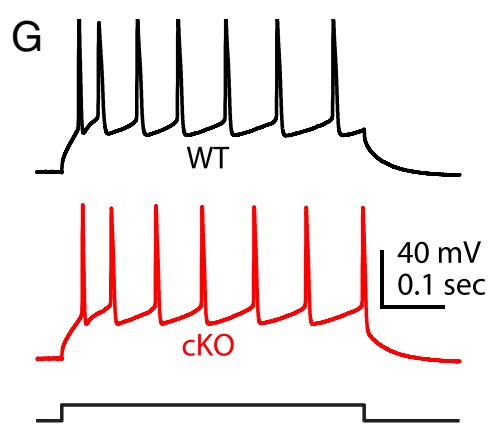

B

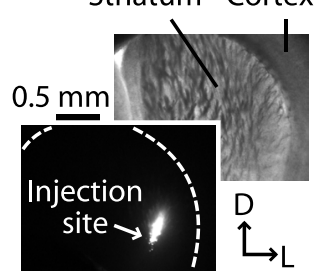

$\mathrm{H}$
C

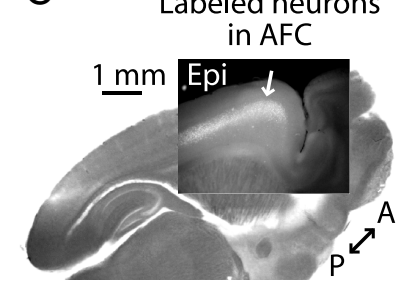

$\mathrm{F}$
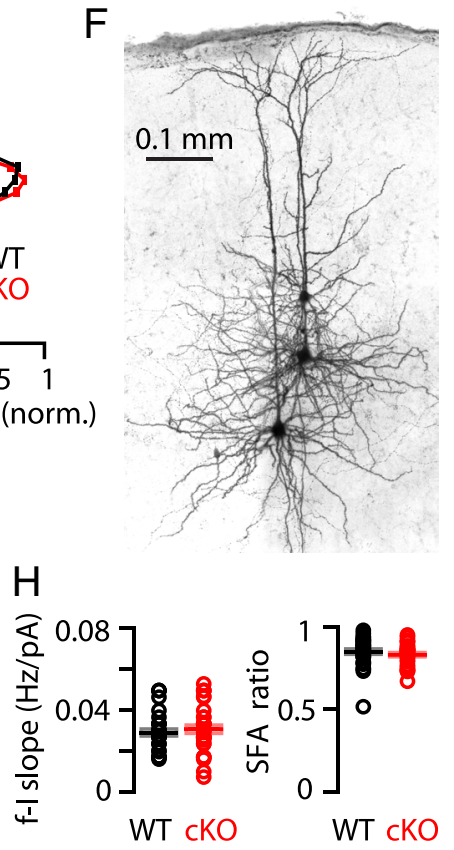

Figure 1. Brain slice preparation of AFC and in vivo labeling of contralaterally projecting corticostriatal neurons. $A$, Schematic depicting retrograde tracer injection in dorsolateral striatum and parasagittal slice angle through the contralateral AFC. $\boldsymbol{B}$, Epifluorescence (bottom left) and bright-field (top right) images of a coronal brain slice showing the injection site in dorsolateral striatum. D, Dorsal; L, lateral. C, Bright-field image of parasagittal brain slice a with superimposed epifluorescence (Epi) image showing labeled corticostriatal neurons in AFC (arrow). A, Anterior; P, posterior. D, Bright-field (BF) and epifluorescence (Epi) images of $A F C$ of a $K 0$ mouse with layers $(\mathrm{L})$ indicated on the left. WM, White matter. $\boldsymbol{E}$, Average normalized fluorescence intensity profiles from WT $(n=20)$ and cKO $(n=10)$ slices. Cortical depth is shown in normalized units of distance (0, pia; 1 , white matter). $\boldsymbol{F}$, Two-photon microscopy image of three patch-recorded corticostriatal neurons in AFC layer 5. G, Examples recorded from WT (top trace, black) and cKO (bottom trace, red) corticostriatal neurons of APs evoked by depolarizing current injection. $\boldsymbol{H}$, Plots of average frequency- current (f-I) slope (left) and spike-frequency adaption (SFA) ratios (right), showing no significant differences between WT and cKO. Circles, Data points from individual neurons; line and box, mean \pm SEM.

to relatively well studied cortical areas such as motor and sensory cortex, there have been no prior investigations of local circuit organization in mouse AFC; similarly, although electrophysiological properties and local circuits of corticostriatal neurons have been described in other cortical areas (Morishima and Kawaguchi, 2006; Hattox and Nelson, 2007; Brown and Hestrin, 2009; Anderson et al., 2010), they have not been characterized in the AFC. Therefore, we developed an experimental approach for in vitro analysis of the circuits of corticostriatal neurons in the AFC.

Stereotaxic injection of fluorescent microspheres in the left striatum (Fig. $1 A, B$ ) resulted in retrograde fluorescent labeling of contralaterally projecting (crossed) corticostriatal neurons in the right AFC (Fig. 1C). Consistent with normal gray and white matter cytoarchitecture (Judson et al., 2009), cortical thickness at the anterior pole (measured in bright-field images of living slices) was not significantly different between wild-type (WT) $\left(\mathrm{Met}^{\mathrm{fx} /{ }^{*}} /\right.$ $\mathrm{WT})$ and conditional knock-out (cKO) $\left(\mathrm{Met}^{\mathrm{fx} / \mathrm{fx} / E m \times l^{\text {cre }}}\right)$ mice (WT: $1.67 \pm 0.02 \mathrm{~mm}$, mean \pm SEM; $n=12$ mice; $\mathrm{cKO}: 1.67 \pm$ $0.02 \mathrm{~mm}, n=7$ mice; $p>0.05, t$ test). Analysis of the laminar

distribution of labeled corticostriatal neurons also showed no difference between cKO and WT (Fig. 1D,E). The density of labeled neurons reached a maximum in upper layer $5 \mathrm{~B}$.

Labeled corticostriatal neurons in these parasagittal AFC brain slices were targeted for whole-cell patch recordings (Fig. $1 F$ ). Neurons from WT $(n=32)$ and cKO $(n=$ 35) mice did not differ significantly in basic electrophysiological parameters, including resting potential (WT, $-70.2 \pm 0.9 \mathrm{mV}$; cKO, $-71.3 \pm 0.9 \mathrm{mV}$; mean $\pm \mathrm{SEM}$; $t$ test, $p>0.05)$ and input resistance (WT, $201.5 \pm 8.9 \mathrm{M} \Omega$; cKO, $192.5 \pm 6.8 \mathrm{M} \Omega ; p>$ $0.05, t$ test). Responses to steps of hyperpolarizing or depolarizing current (Fig. 1G) showed no differences between WT and cKO neurons in frequency-current slopes (WT, $0.055 \pm 0.002 \mathrm{~Hz} / \mathrm{pA}$; cKO, $0.056 \pm$ $0.002 \mathrm{~Hz} / \mathrm{pA} ; p>0.05, t$ test) or spikefrequency adaption ratios (WT, $0.85 \pm 0.02$; cKO, $0.83 \pm 0.01 ; p>0.05, t$ test) (Fig. $1 H$ ). These properties were measured just before LSPS mapping, thus under conditions optimized for mapping rather than for intrinsic property analysis.

These characterizations validate these methods as an experimental paradigm for studying crossed corticostriatal neurons, a major class of excitatory projection neurons, in the AFC of mice and demonstrate that the laminar distributions and basic electrophysiological properties of these neurons were similar in $\mathrm{cKO}$ and $\mathrm{WT}$ animals.

\section{Circuit mapping with LSPS}

To examine cortical circuit organization in cKO animals, we used glutamate uncaging and LSPS (Callaway and Katz, 1993; Katz and Dalva, 1994; Shepherd et al., 2003; Shepherd, 2011) as a quantitative tool for mapping local sources of excitatory input to individual postsynaptic neurons. Brain slices containing AFC harvested from P21 to P32 were placed in the recording chamber and bathed with ACSF containing caged glutamate. Fluorescently labeled corticostriatal neurons were targeted for patch recording. Brief $(1 \mathrm{~ms})$ flashes of focused UV laser light caused photo-release of glutamate at discrete locations in the slice, in turn causing a small population of neurons to depolarize sufficiently to fire APs. Excitatory connections from the stimulated presynaptic neurons onto the postsynaptic neuron were recorded as EPSCs in voltage-clamp mode (Fig. 2A,B). By stimulating sequentially over an array of hundreds of locations, a spatial array of traces was collected (Fig. 2C). These data were converted to synaptic input maps (Fig. $2 D$ ) by calculating the mean response amplitude in a $50 \mathrm{~ms}$ poststimulus window. Responses that were contaminated by direct somatodendritic stimulation were excluded (black pixels in maps). These synaptic input maps revealed regions of strong excitatory input (such as layer 2/3) (Fig. 2D,E), representing the locations of pyramidal neurons presynaptic to the recorded neuron. 


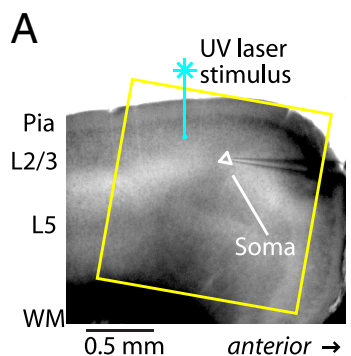

F

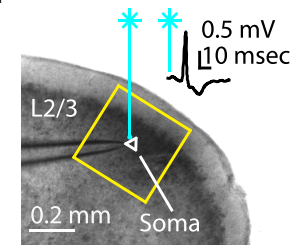

B



G



C

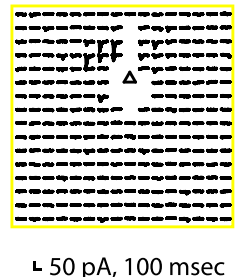

$\mathrm{H}$

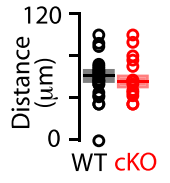

D

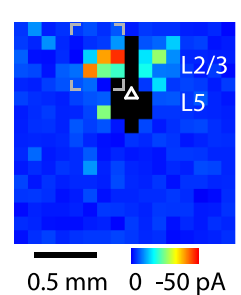

J

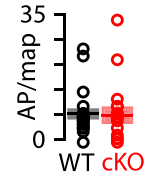

E

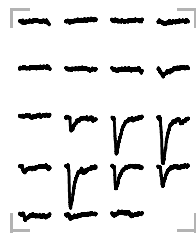

L 25 pA, $50 \mathrm{msec}$

$\mathrm{K}$



Figure 2. Synaptic input mapping in AFC slices. A, Bright-field image showing recording arrangement, including orientation of the 256-site stimulus grid (yellow box), a single stimulus location $\left({ }^{*}\right)$, and the soma of the recorded neuron (triangle). $\boldsymbol{B}$, Example of EPSC evoked by glutamate uncaging at one stimulus location. $\boldsymbol{C}$, Array of traces recorded during sequential photostimulation at the 256 sites in the stimulus grid. Responses that were contaminated by direct stimulation of the postsynaptic neuron's dendrites are blank. D, Synaptic input map. Pixel values represent the mean current over a $50 \mathrm{~ms}$ poststimulus time window. Black pixels represent traces contaminated by dendritic responses. $\boldsymbol{E}$, Traces from region of interest (ROI) (gray brackets in $\boldsymbol{D}$ ) showing strong layer $2 / 3$ inputs for this neuron. $F$, Excitation profile. This example shows an AP evoked by perisomatic stimulation of a cKO layer $2 / 3$ pyramidal neuron, recorded in cell-attached mode. The location of the stimulus grid is indicated by the yellow box. G, APs occurred at several locations immediately surrounding the soma. $\boldsymbol{H}$, Mean distance of AP-generating sites from the soma, an estimator of the spatial resolution of photostimulation $\left(V_{\text {exc }}\right)$, did not differ in WT and cKO. Circles, Data points from individual neurons; line and box, mean \pm SEM. $I$, Total number of APs per excitation profile, an estimator of the intensity of photostimulation ( $N_{A P}$ ), did not differ in WT and cK0.J, Example of a Nissl-stained section of AFC (in a WT mouse). Cells were counted within a $0.1 \times 0.2 \mathrm{~mm}$ ROl in layer $2 / 3$ (box and inset) to assess relative cell density. $\boldsymbol{K}$, Number of layer $2 / 3$ neurons per ROl, expressed as cells per $10,000 \mu \mathrm{m}^{2}$ in a $50-\mu \mathrm{m}$-thick slice $\left(\rho_{\text {cell }}\right)$, did not differ in WT and cK0.

Pixel values $\left(Q_{\text {con }}\right)$ in synaptic input maps reflect a combination of (1) the total number of APs evoked in the small groups of presynaptic neurons at the stimulus location and (2) the average connection strength $\left(I_{\text {con }}\right)$ between the activated presynaptic neurons and the individually recorded postsynaptic neuron (Bureau et al., 2004, 2008; Shepherd et al., 2005; Weiler et al., 2008). $I_{\text {con }}$ reflects the product of the unitary connection probability $\left(p_{\text {con }}\right)$ and unitary connection strength $\left(i_{\text {con }}\right)$ :

$$
I_{\text {con }}=p_{\text {con }} \cdot i_{\text {con }} \text {. }
$$

The total numbers of neurons and APs activated per flash are influenced by neuronal density $\left(\rho_{\text {cell }}\right)$ and the resolution (e.g., excitation volume, $V_{\text {exc }}$ ) and intensity (number of APs, $N_{\mathrm{AP}}$ ) of photostimulation. Combining these terms, gives the following:

$$
Q_{\text {con }}=\left(\rho_{\text {cell }} \cdot V_{\text {exc }} \cdot N_{\mathrm{AP}}\right) \cdot I_{\text {con }} \text {. }
$$

To estimate $V_{\text {exc }}$ and $N_{\mathrm{AP}}$ for the conditions used here, we recorded "excitation profiles" of layer $2 / 3$ pyramidal neurons (Fig. $2 F-K$ ), as these were the presynaptic neurons of interest (i.e., presynaptic to layer 5 neurons). We analyzed the excitation profile data and extracted parameters representing the resolution and intensity of photostimulation. The mean distance of APgenerating sites from the soma, an estimator of the resolution of photostimulation (closely related to $V_{\text {exc }}$ ), was not significantly different in WT and cKO slices (WT: $61.9 \pm 5.3 \mu \mathrm{m}$, mean \pm SEM; $n=25$; cKO: $56.6 \pm 5.2 \mu \mathrm{m}, n=17 ; p>0.05, t$ test) (Fig. $2 H)$. This parameter also did not differ when the vertical and horizontal distances were considered separately. The total number of APs per excitation profile, an estimator of the intensity of photostimulation (closely related to $N_{\mathrm{AP}}$ ), also did not differ by genotype (WT: $7.9 \pm 1.2, n=25$; cKO: $7.6 \pm 2.1, n=17 ; p>0.05$, $t$ test) (Fig. $2 I$ ). Neuronal density was assessed in Nissl-stained slices of AFC by counting the number of neurons in a defined region of interest in layer $2 / 3$ (Fig. $2 J$ ). Relative neuronal density, an estimator of $\rho_{\text {cell }}$, did not differ between WT and cKO animals (WT: $37.1 \pm 2.1$ cells/10,000 $\mu \mathrm{m}^{2}, n=12$ slices; cKO: $36.9 \pm$ 1.0 cells $/ 10,000 \mu \mathrm{m}^{2}, n=12$ slices; $p>0.05, t$ test) (Fig. $2 \mathrm{~K}$ ).

These LSPS control experiments indicate that the efficacy of photostimulation was similar in WT and cKO slices. This implies that any differences observed in synaptic input maps (i.e., in pixel values, or $\left.Q_{\text {con }}\right)$ reflects differences in connectivity $\left(I_{\text {con }}\right)$, rather than differences in LSPS excitation parameters $\left(\rho_{\text {cell }}, V_{\text {exc }}, N_{\mathrm{AP}}\right)$.

In this study, we use the term "connectivity" to refer to $I_{\text {con }}$, which, as the product of connection probability and amplitude, reflects the overall "strength" or "impact" of connections in a synaptic pathway (Lefort et al., 2009). The term "hyperconnectivity" thus refers to an increase in $I_{\text {con }}$, resulting from an increase in either $p_{\text {con }}$ or $i_{\text {con }}$, or both.

\section{Layer 2/3 inputs to layer 5B corticostriatal neurons are increased in Met-cKO slices}

We recorded from corticostriatal neurons in the AFC of Met-cKO and WT mice and mapped excitatory synaptic inputs with LSPS. Map data were analyzed in several ways to understand the circuit organization. First, we averaged all the maps in each group (equivalent to a front view of the data set) (Fig. 3A). The average WT map (Fig. $3 B$ ) showed strong excitatory input arising from layer $2 / 3$ and weaker input from nearby in layer 5 , much like the topography observed in primary motor cortex (Weiler et al., 2008; Anderson et al., 2010). The average cKO map (Fig. 3C) showed similar topography but a trend toward greater amplitude of layer $2 / 3$ input; however, this difference did not reach statistical significance (WT: $-16.6 \pm 2.8 \mathrm{pA}, n=32$ neurons; cKO: $-20.8 \pm 2.3 \mathrm{pA}, n=35$ neurons; $p>0.05, t$ test $)$.

A potential complication in studying a particular class of cortical pyramidal neurons defined by their long-range projections alone is that local circuits can differ greatly depending on the precise sublayer locations of the neurons' somata (Otsuka and 
A

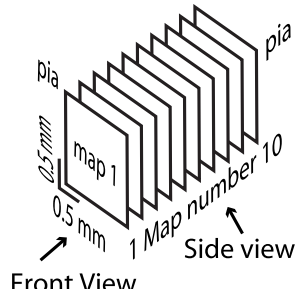

Front View

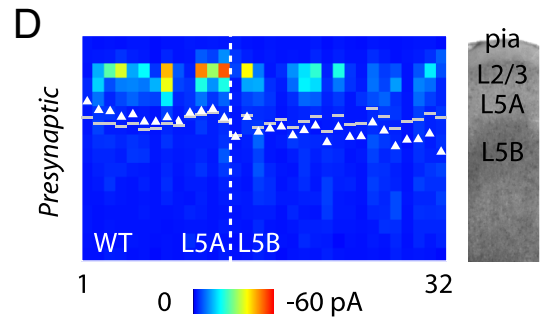

$\mathrm{E}$

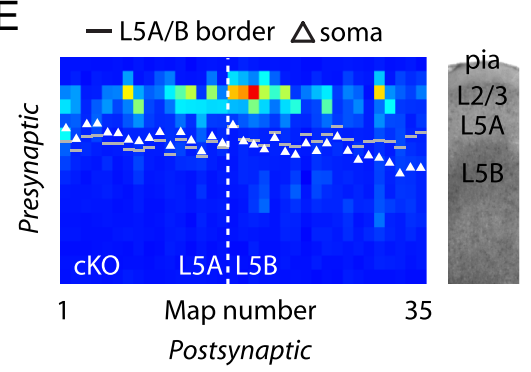

$\mathrm{H}$


C

Avg maps, all corticostriatal neurons

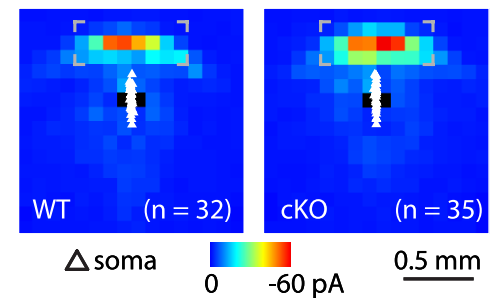

$\mathrm{F}$

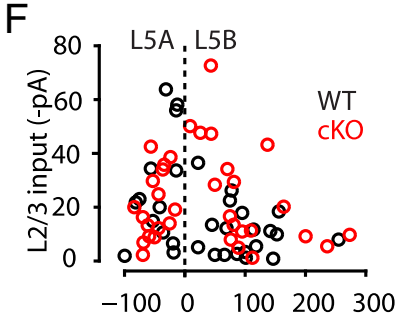

G

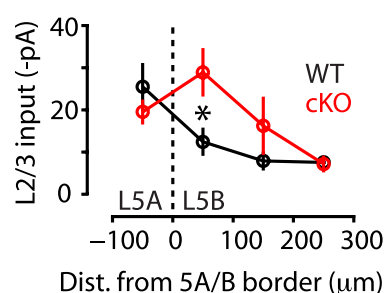

Dist. from $5 A / B$ border $(\mu \mathrm{m})$

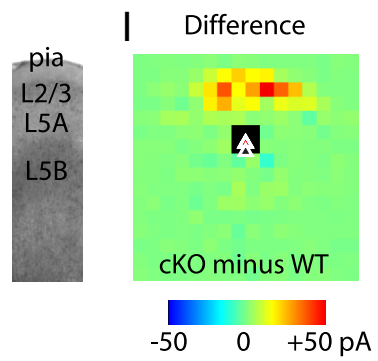

Figure 3. Layer $2 / 3$ inputs to layer $5 B$ corticostriatal neurons are stronger in Met-cK0 slices. $A$, Projecting the data in a stack of input maps as an average front view (averaging all the maps) and a side view (averaging along map rows). $\boldsymbol{B}$, Average WT input maps. White brackets indicate region of interest used for calculating average input. Triangles, Soma positions of the recorded neurons. C, Average cKO input maps. D, Maps of 32 WT neurons projected by averaging along map rows, yielding a side view of the map data set (see $\boldsymbol{A}$ ). Each column in the image corresponds to an individual neuron's synaptic input map, averaged along map rows. The data were sorted by the distance of the soma from the layer $5 \mathrm{~A} / \mathrm{B}$ border from highest (closer to pia) to lowest. The vertical white line separates layer $5 A$ neurons (on the left) from layer $5 B$ neurons (on the right). The apparent jitter in soma positions (white triangles) arises from differences in the absolute distances of the layer $5 \mathrm{~A} / \mathrm{B}$ border relative to the pia (gray lines). $\boldsymbol{E}$, Side view of cKO maps. $\boldsymbol{F}$, Layer 2/3 input, plotted as a function of the somatic location of the recorded corticostriatal neurons relative to the layer $5 \mathrm{~A} / \mathrm{B}$ border. $\boldsymbol{G}$, Same data as in $\boldsymbol{F}$, averaged in $100 \mu \mathrm{m}$ bins. The asterisk indicates statistically significant difference between groups. $\boldsymbol{H}$, Input maps for corticostriatal neurons in upper layer $5 B$. I, Input map obtained by subtracting the WT from the CKO maps in $\boldsymbol{H}$.

Kawaguchi, 2008; Anderson et al., 2010). We therefore also analyzed the maps of these corticostriatal neurons by sorting them according to soma location relative to the layer 5A/B border (superficial to deep). Projecting the sorted map data onto a single plane by averaging along the map rows gave a side view of the maps (Fig. $3 A, D, E$ ), providing a quantitative description of the local circuit in terms of the sublayer locations of the presynaptic pyramidal neurons and postsynaptic corticostriatal neurons. In the side-view maps, the apparent jitter in soma positions arises from variability in the distances of the layer $5 \mathrm{~A} / \mathrm{B}$ border from the pia.
Plotting the average strength of input from layer $2 / 3$ to corticostriatal neurons as a function of the distance of the postsynaptic neuron's soma from the layer 5A/B border (Fig. $3 F, G$ ) showed that, on average, the amplitude of layer $2 / 3$ excitatory input to corticostriatal neurons in upper layer $5 \mathrm{~B}$ was greater in the $\mathrm{cKO}$ compared with WT by a factor of 2.3 (WT: $-12.3 \pm 3.3 \mathrm{pA}, n=11$; cKO: $-28.6 \pm$ $5.7 \mathrm{pA}, n=12$; $p<0.05$, $t$ test). To visualize the circuit differences, we generated average maps for just the neurons located in upper layer 5B neurons (where the difference was maximal; $n=11 \mathrm{WT}$ and 12 cKO neurons) (Fig. $3 \mathrm{H}$ ) and computed a difference image by subtracting the WT map from the cKO map (Fig. 3I). This revealed a locus of maximal difference in layer $2 / 3$.

\section{Similarity of Met-heterozygous and Met-cKO circuits}

In the preceding experiments, we used Met-cKO mice engineered to eliminate Met signaling in tissue derived from the dorsal pallium. However, both rare lossof-function copy number variation (Marshall et al., 2008; Pinto et al., 2010) and the common SNP allelic association of MET with ASD result in a reduction, rather than complete absence, of gene and protein expression (Campbell et al., 2006, 2007). Therefore, to assess whether partial disruption of Met signaling in the forebrain affects cortical circuits, we also studied Metheterozygous (HET) mice $\left(\mathrm{Met}^{\mathrm{f} \mathrm{x} /+} /\right.$ $\left.E m \times 1^{\text {cre }}\right)$, in which Met expression in the forebrain is reduced by $\sim 50 \%$ (determined by forebrain Western blot analysis; M. C. Judson and P. Levitt, unpublished observations).

In HET mice, corticostriatal neurons occupied the same laminar distribution as in WT and $\mathrm{CKO}$ (Fig. $4 A, B$ ). Corticostriatal neurons in both layer $5 \mathrm{~A}$ and $5 \mathrm{~B}$ received inputs from layer $2 / 3$, as seen in a side-view projection of their input maps (Fig. 4C). Plotting layer $2 / 3$ input as a function of sublayer location showed that, like the cKO (see above), the inputs in HET mice differed from WT in layer $5 \mathrm{~B}$ (Fig. $4 D, E$ ). Layer $2 / 3$ inputs to both the HET and $\mathrm{CKO}$ layer $5 \mathrm{~B}$ corticostriatal neurons were more than doubled compared with the WT (WT, $-10.4 \pm 2.1 \mathrm{pA}$; HET, $-21.5 \pm 3.9 \mathrm{pA}$; cKO, $-23.0 \pm 4.3 \mathrm{pA}$; one-way ANOVA, $p<$ $0.05)$. These results indicate that even partial reduction of Met signaling is sufficient to alter local circuits in the frontal cortex of mice.

\section{Stronger unitary connections in Met-cKO neurons}

The LSPS data indicate that excitatory intracortical synaptic pathways are abnormally strengthened in cKO mice, but this 
provides indirect evidence about the strengths of unitary connections between individual presynaptic and postsynaptic neurons. Therefore, we performed paired recordings to measure the properties of unitary connections from layer $2 / 3$ neurons onto radially subjacent layer $5 \mathrm{~B}$ corticostriatal neurons (Fig. 5A). APs were induced in the layer $2 / 3$ neuron while recording from the corticostriatal neuron in voltage-clamp mode (Fig. 5B). In WT slices, excitatory connections were found for 8 of 76 paired recordings (i.e., $p_{\text {con }}=$ 0.11 ), comparable to $p_{\text {con }}$ for layer $2 / 3 \rightarrow 5$ connections in mouse barrel cortex $[\sim 0.1$ (Lefort et al., 2009)]. In cKO slices, excitatory connections were found for 7 of 41 paired recordings $\left(p_{\text {con }}=0.17\right)$. This difference between WT and cKO (a factor of 1.6) (Fig. 5C) did not reach statistical significance, presumably because of the low numbers of connected pairs $(p>0.05$; $\mathrm{df}=1$; two-sample $\chi^{2}$ test with Yates' correction). On average, the strength of unitary EPSCs (uEPSCs) between connected pairs was significantly greater in cKO neurons compared with WT by a factor of 1.4 (WT: $-27.1 \pm 0.9 \mathrm{pA}, n=8$ pairs; cKO: $-37.1 \pm 2.8, n=7$ pairs; $p<0.05, t$ test $)$ (Fig. 5D).

To relate these unitary connection measurements to LSPS mapping data, we considered that a pixel value is proportional to the average connection strength [i.e., $\left(Q_{\text {con }} \sim I_{\text {con }}\right)$ (see Eq. 2)] and that $I_{\text {con }}$ is the product of the unitary connection probability $\left(p_{\text {con }}\right)$ and amplitude $\left(i_{\text {con }}\right)$ (see Eq. 1) (see also Lefort et al., 2009). This is equivalent to pooling connected and unconnected pairs. In $\mathrm{cKO}, I_{\text {con }}$ was greater by a factor of 2.4 compared with WT (cKO, $6.3 \mathrm{pA}$; WT, $3.0 \mathrm{pA}$ ), a difference that was significant when calculated based on the product $p_{\text {con }} \times i_{\text {con }}(p<0.05, t$ test $)$, although not when based the pooled data ( $p>0.05$, Wilcoxon test). The greater difference in $I_{\text {con }}$ than in $i_{\text {con }}$ reflects the higher $p_{\text {con }}$ observed for cKO pairs. The magnitude of the difference (factor of 2.1) is consistent with the magnitude of the differences in $Q_{\text {con }}$ measured by LSPS (factor of 2.3).

In principle, differences in short-term plasticity could also contribute to differences in LSPS maps and, moreover, would implicate presynaptic mechanisms. We therefore tested the paired-pulse ratios of the UEPSCs in the connected pairs, during which three current pulses ( $1 \mathrm{~ms}$ duration, $1 \mathrm{nA}, 50 \mathrm{~ms}$ interval) were injected into the presynaptic layer $2 / 3$ neurons to elicit single APs. The paired-pulse ratios of uEPSCs in the postsynaptic L5B corticostriatal neurons were calculated as the amplitude ratios over the first uEPSC. We found that paired-pulse ratios for WT $(n=5)$ and cKO $(n=5)$ did not differ (two-way ANOVA, $p>0.05$ for the effects of genotype). These results suggest that at least some functional presynaptic mechanisms for synaptic strengthening (e.g., involving changes in release probability) do not contribute directly to the circuit phenotype. The data, however, do not exclude the possibility of presynaptic involvement in the observed strengthening of the layer $2 / 3$ inputs onto layer $5 \mathrm{~B}$ corticostriatal neurons (for example, increased numbers of release sites).

\section{Projection class specificity of circuit changes in Met-cKO mice}

In preceding experiments, we focused on the population of contralaterally projecting corticostriatal neurons, a pyramidal neuronal class that normally expresses Met. However, Met is expressed in both layer $2 / 3$ pyramidal neurons and layer $5 \mathrm{~B}$ corticostriatal neurons, and cell-nonautonomous effects of Met deletion on postsynaptic neuronal structure can occur (Judson et al., 2010). Therefore, the impact of Met deficiency on layer $2 / 3$ input strength could be a result of mechanisms that are presynaptic, postsynaptic, or both. In particular, layer $2 / 3$ input could be stronger to all layer $5 \mathrm{~B}$ neurons, independent of their long-range projection targets. To test these ideas, we selected for additional physiological analyses a class of neurons that does not normally express Met and therefore might be less affected by potential cell-autonomous effects of Met deficiency in the cKO mice. Based on immunocytochemical mapping, Met expression is low or absent in the axons of corticopontine neurons that project in the cerebral peduncle (Judson et al., 2009). Corticopontine neurons thus provide a comparison group by which to separate the effects of sublayer location from postsynaptic Met expression. Because the paired-pulse ratio data implicated postsynaptic rather than presynaptic effects of Met deficiency on circuits of (normally Met-expressing) layer 5B corticostriatal neurons (Fig. $5 F$ ), we hypothesized that Met deficiency would not affect the circuits of (normally Met-nonexpressing) layer 5B corticopontine neurons.

To label AFC neurons projecting to the pons, we injected fluorescent microspheres into the pontine nuclei and cerebral peduncle and prepared brain slices containing the ipsilateral AFC (Fig. 6A). Because both Met-heterozygous $\left(\mathrm{Met}^{\mathrm{fx} /+} / E m \times 1^{\text {cre }}\right)$ and $M e t-c K O\left(M e t^{\mathrm{fx} / \mathrm{fx}} / E m \times 1^{\text {cre }}\right)$ corticostriatal neurons showed 
A



B



C

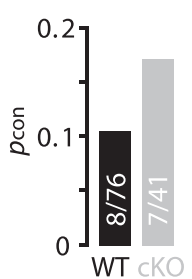

D

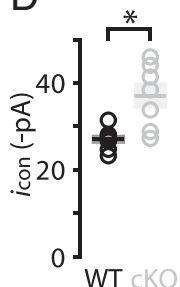

$\mathrm{E}$

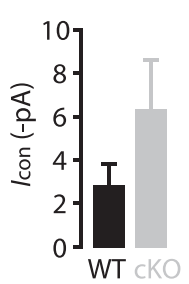

F



Figure 5. Unitary connectivity is increased in Met-CKO.A, Bright-field image of slice showing paired recording arrangement. $\boldsymbol{B}$, Example of connection from a layer $2 / 3$ neuron to a layer $5 B$ corticostriatal neuron in a cKO slice. $C$, Overall connection probability $\left(p_{\text {con }}\right)$. D, Mean uEPSC amplitude for connected pairs $\left(i_{\text {con }}\right)$. Circles, Data points from individual neurons; line and box, mean \pm SEM. The asterisk indicates significant difference $(p<0.05, t$ test). $\boldsymbol{E}$, Mean connection amplitude for all pairs $\left(I_{\text {con }}\right)$. $\boldsymbol{F}$, Average paired-pulse ratio (PPR), calculated as the amplitude of the first, second, or third uEPSC relative to the first, did not differ in WT (black) and cKO (gray).

the same degree of local circuit strengthening (Fig. 4), we grouped the two genotypes (hereafter $\mathrm{Met}^{\mathrm{fx} /{ }^{*}} / E m x 1^{\text {cre }}$ ) for the subsequent comparisons with controls $\left(\mathrm{Met}^{\mathrm{fx} / *} / \mathrm{WT}\right)$. Fluorescently labeled corticopontine projection neurons were located exclusively in layer 5B (Fig. 6B). LSPS front-view map averages showed similar topography of input from layer $2 / 3$ for both groups (Fig. 6C,D). Quantification of this input as a function of soma position within layer 5 (Fig. $6 E$ ) revealed that the layer $2 / 3$ input strength was not increased for the $\mathrm{Met}^{\mathrm{fx} / *} / E m \times 1^{\text {cre }}$ corticopontine neurons $\left(\mathrm{Met}^{\mathrm{fx} / *} / \mathrm{WT}:-28.5 \pm 3.3 \mathrm{pA}, n=34 ; \mathrm{Met}^{\mathrm{fx} / *} /\right.$ Emx $1^{\text {cre }}:-33.2 \pm 5.4 \mathrm{pA}, n=19 ; p>0.05, t$ test) (Fig. $6 F$ ). These data indicate that, at least for cortical circuits, the synaptic abnormalities of local circuit excitatory connectivity in Met-deficient mice are projection class specific.

\section{Discussion}

While the number of candidate genes continues to increase (Abrahams and Geschwind, 2010), the functional link between genetic risk for ASD and cortical circuitry remains a significant challenge to define. The main finding of this study demonstrates a significant increase in intracortical connectivity in local excitatory circuits of AFC in mice with disrupted cortical expression of Met (Fig. 7). Although MET typically is not included in models of key synaptic proteins that may contribute to ASD pathogenesis, the current electrophysiological data and our recent results of altered dendritic and spine development in Met-cKO mice (Judson et al., 2010) indicate that the contribution of MET to
A

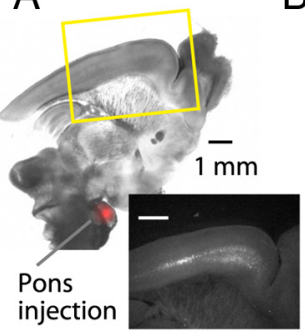

B

C
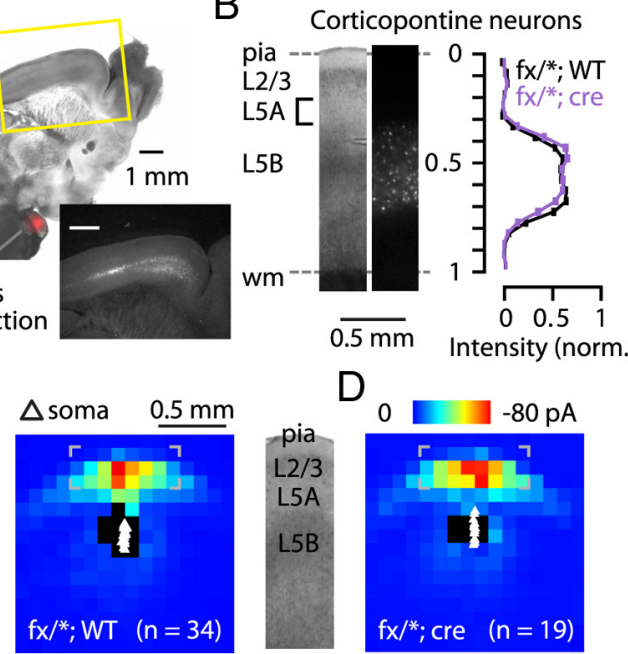

D
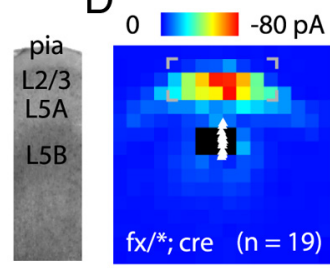

E

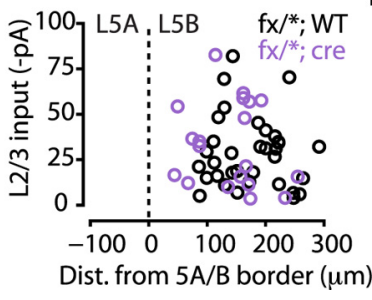

F $\quad f x / \%$;

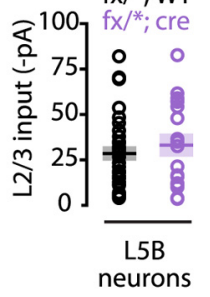

Figure 6. Local circuit strengthening in Met-cKO mice does not occur for corticopontine projection neurons in the AFC. $A$, Retrograde labeling of corticopontine neurons. A red fluorescent tracer was injected into the pons and cerebral peduncle. Inset, Epifluorescence image of labeled corticopontine neurons in AFC layer 5B. B, Laminar distribution of corticopontine neurons. Example bright-field and epifluorescence images (left) and average fluorescent intensity profiles (right) for Met ${ }^{\mathrm{fx} / *} / \mathrm{WT}$ ( $n=13$ mice) and $\mathrm{Met}^{\mathrm{fx} / *} / \mathrm{Emx} 7^{\mathrm{cre}}:(n=8)$ mice are shown. $C$, D, Front-view average maps of $\operatorname{Met}^{\mathrm{fx} / *} / \mathrm{WT}(n=34)$ and $\operatorname{Met}^{\mathrm{fx} / *^{*} / E m \times 7^{\text {(re }}}(n=19)$ corticopontine neurons show that both groups received layer 2/3 inputs (bounded with gray brackets). $\boldsymbol{E}$, Layer 2/3 input plotted as a function of the somatic location of the recorded corticopontine neurons relative to the layer $5 \mathrm{~A} / \mathrm{B}$ border. All the corticopontine neurons are in layer $5 B$. $F$, Synaptic input from layer $2 / 3$ (averaged over the region of interest indicated by the brackets in $($ and $D$ ) to layer $5 B$ corticopontine neurons recorded in slices prepared from $\mathrm{Met}^{\mathrm{fx/*}} / \mathrm{WT}$ and $\mathrm{Met}^{\mathrm{fx} /{ }^{*} / E m x} 1^{\text {(re }}$ mice $(p>0.05, t$ test). Circles, Data points from individual neurons; line and box, mean \pm SEM.
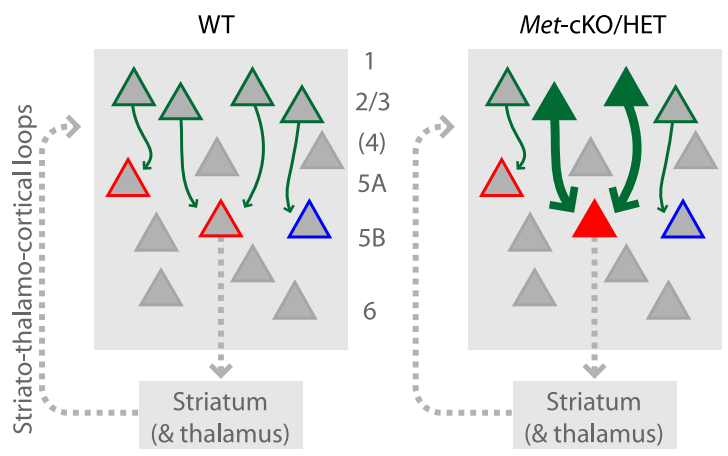

Figure 7. Schematic summary of the main microcircuit changes in Met-cKO. Left, The main microcircuits in AFC ofWT mice involve connections from layer 2/3 pyramidal neurons (green) to corticostriatal (red) and corticopontine (blue) neurons in layer 5A and 5B. Right, In Met-cKO and HET mice, hyperconnectivity in the excitatory microcircuit from layer $2 / 3$ pyramidal neurons to layer $5 \mathrm{~B}$ corticostriatal neurons is indicated by filled triangles and thicker arrows. Corticostriatal neurons participate in large-scale loops through the basal ganglia, thalamus, and cortex.

ASD risk is consistent with the model of disrupted synaptic development in specific circuits that underlie social behavior and communication (Zoghbi, 2003; Persico and Bourgeron, 2006; Sudhof, 2008). 


\section{Circuit specificity of Met disruption and implications for ASD}

We focused on characterizing the excitatory inputs from layer $2 / 3$ pyramidal neurons to layer 5 corticostriatal neurons, as our mapping studies in WT animals revealed this pathway as the primary source of interlaminar input to these neurons. We found this pathway to be hyperconnected both in Met-cKO and Met-HET mice. This was manifest as increased amplitude of synaptic inputs $\left(Q_{\text {con }}\right)$ in LSPS maps (Fig. 3) and increased synaptic connectivity $\left(I_{\text {con }}\right)$ in paired recordings (Fig. 5). Perhaps most surprising was the remarkably specific impact of Met deficiency on cortical microcircuits. A specific subpopulation of corticostriatal neurons exhibited hyperconnectivity (neurons just below the layer 5A/B border), and, moreover, layer 5 pyramidal neurons that do not express Met (corticopontine neurons) failed to show changes in local circuits in our experiments (Fig. 7). The data suggest that the spatial regulation of Met expression will be a key element in deciphering which circuits in the human brain are most vulnerable to MET genetic risk. Our recent study in the developing monkey, in which we demonstrate high levels of MET expression in restricted areas of frontal, temporal, and occipital cortex, amygdala, and hippocampus during synapse formation, suggest that in humans, vulnerability is likely to impact specific circuits that are involved in emotional face and complex image processing (Judson et al., 2011). In the affected circuits in the mouse, the hyperconnectivity was manifest as increased amplitude of average connectivity in LSPS maps (Fig. 3) and as increased unitary connectivity in pair recordings (Fig. 5). Although the behavioral significance of these microcircuit-level changes needs to be tested, the consistency of our data with predictions of local neocortical hyperconnectivity from human neuroimaging studies in clinical populations is striking (Frith, 2004; Just et al., 2004, 2007; Courchesne and Pierce, 2005; Geschwind and Levitt, 2007; Scott-Van Zeeland et al., 2010).

\section{Comparison with other mouse models used to study ASD}

Mouse models of ASD-related neurodevelopmental disorders are increasingly available, particularly for monogenic and syndromic disorders (for review, see Ehninger et al., 2008; Moy and Nadler, 2008). Changes in cortical circuit organization have been described in some of these and are interesting to compare to the present results. In Fmr1-mutant mice, a model of Fragile X syndrome, excitatory drive in somatosensory microcircuits is reduced (Gibson et al., 2008; Pfeiffer and Huber, 2009), including a developmentally transient decrease in layer $4 \rightarrow 2 / 3$ connectivity that normalizes by early adulthood (Bureau et al., 2008). In Mecp2-mutant mice, a model of Rett syndrome, excitatory connections between layer 5 pyramidal neurons in somatosensory cortex show a developmentally enduring decrease in connectivity (Dani et al., 2005; Dani and Nelson, 2009), and ascending excitatory pathways to layer $2 / 3$ pyramidal neurons in motor cortex also show reduced excitatory synaptic connectivity (Wood et al., 2009; Wood and Shepherd, 2010), consistent with reduced connectivity observed in monocultures (Chao et al., 2007). In contrast, in the present study using a mouse model with a disrupted risk gene of idiopathic ASD, we found evidence for hyperconnectivity in local excitatory circuits in the AFC. The differences may reflect a substantial level of complexity with which ASD risk genes contribute to abnormal cortical circuit development, which in turn may be relevant to the well known heterogeneity of even the core behavioral triad of clinical phenotypes that comprise the ASD diagnosis in different populations.

Prenatal exposure to valproic acid (VPA) is a relevant nongenetic model related to ASD that can be compared with our find- ings. Exposure to VPA during a short critical period early in embryonic development significantly increases the risk of a child being diagnosed with ASD (Rasalam et al., 2005). In rats exposed in utero to VPA, layer 5 pyramidal neurons in somatosensory and frontal cortices exhibit recurrent excitatory hyperconnectivity in the form increased connection probability (Rinaldi et al., 2008a,b), similar to our findings of increased connectivity. However, in the VPA model, the mean amplitude of unitary connections was reduced (here, increased); moreover, intrinsic excitability was strongly attenuated (here, unchanged). The underlying mechanism through which VPA induces local circuit changes is unknown, but the drug can alter gene expression in complex ways (Milutinovic et al., 2007), and furthermore may affect cortical excitation/inhibition balance by depleting specific populations of neocortical interneurons (Gogolla et al., 2009).

\section{Functional implications of aberrant cortical microcircuits}

The consequences of local-circuit hyperconnectivity on cortical function remain unknown. It has been speculated that an excessive ratio of excitation to inhibition generates "noise" in cortical signaling and sensory representations (Rubenstein and Merzenich, 2003; Levitt et al., 2004). Computational modeling has also been used to explore how hyperconnectivity in cortical circuits leads to greater transformation of the information being processed through the local circuit (Neymotin et al., 2010). Our results provide experimental data that could be used to constrain and extend such theoretical approaches. Moreover, some individuals with ASD display a "hyperperception" within a sensory domain (Iarocci and McDonald, 2006; Baron-Cohen et al., 2009), which might arise from local-circuit hyperconnectivity. These circuit-level and related changes could also lead to an "intense world syndrome" (Markram et al., 2007; Markram and Markram, 2010).

Our findings may also relate to the types motor and action planning abnormalities characteristic of ASD (Teitelbaum et al., 1998; Haswell et al., 2009; Mostofsky et al., 2009). The cell-class specificity, affecting the corticostriatal projection both at the level of local cortical circuits (present study) and at the level of medium spiny neurons in the striatum (Judson et al., 2010), is consistent with the clinical picture of stereotypies and repetitive behaviors, which point to dysfunction in the extrapyramidal motor system including large-scale loops involving cortex, basal ganglia, and thalamus (Hallett et al., 1993; Haznedar et al., 2006). Thus, together with our recently reported influence of Met signaling on dendritic tree morphology and spine size (Judson et al., 2010), the present data provide a unique translation of the genetic risk of MET for ASD into a neurobiological mechanism with relevance to the core clinical phenotype (Campbell et al., 2010).

Our study raises many questions about other aspects of cortical organization that may be altered by Met deficiency. For example, the experimental paradigm used here could be applied to other cell classes, cortical areas, and developmental time points. The possibility of abnormal inhibitory mechanisms also remains to be explored at the microcircuit level. Evaluation of even more restricted models of Met deficiency, such as single-cell knock-down approaches (Wood et al., 2009) would help to understand the extent to which the changes observed here are presynaptic versus postsynaptic, cell-autonomous versus cell-nonautonomous, and "primary" versus "compensatory" ("adaptive").

In summary, our analysis establishes a pattern of excitatory hyperconnectivity in specific AFC microcircuits caused by Met deficiency. We propose that these changes constitute a circuitlevel physiological basis for Met-mediated ASD risk. The findings 
reported here provide a starting point, including a quantitative topographic map, to guide further exploration of how Met signaling influences cortical circuit development.

\section{References}

Abrahams BS, Geschwind DH (2010) Connecting genes to brain in the autism spectrum disorders. Arch Neurol 67:395-399.

Anderson CT, Sheets PL, Kiritani T, Shepherd GM (2010) Sublayer-specific microcircuits of corticospinal and corticostriatal neurons in motor cortex. Nat Neurosci 13:739-744.

Baron-Cohen S, Ashwin E, Ashwin C, Tavassoli T, Chakrabarti B (2009) Talent in autism: hyper-systemizing, hyper-attention to detail and sensory hypersensitivity. Philos Trans R Soc Lond B Biol Sci 364:1377-1383.

Blue ME, Parnavelas JG (1983) The formation and maturation of synapses in the visual cortex of the rat. II. Quantitative analysis. J Neurocytol 12:697-712.

Bronner-Fraser M (1995) Hepatocyte growth factor/scatter factor (HGF/ $\mathrm{SF}$ ) in early development: evidence for a role in neural induction. Trends Genet 11:423-425.

Brown SP, Hestrin S (2009) Intracortical circuits of pyramidal neurons reflect their long-range axonal targets. Nature 457:1133-1136.

Bureau I, Shepherd GM, Svoboda K (2004) Precise development of functional and anatomical columns in the neocortex. Neuron 42:789-801.

Bureau I, Shepherd GM, Svoboda K (2008) Circuit and plasticity defects in the developing somatosensory cortex of FMR1 knock-out mice. J Neurosci 28:5178-5188.

Callaway EM, Katz LC (1993) Photostimulation using caged glutamate reveals functional circuitry in living brain slices. Proc Natl Acad Sci U S A 90:7661-7665.

Campbell DB, Sutcliffe JS, Ebert PJ, Militerni R, Bravaccio C, Trillo S, Elia M, Schneider C, Melmed R, Sacco R, Persico AM, Levitt P (2006) A genetic variant that disrupts MET transcription is associated with autism. Proc Natl Acad Sci U S A 103:16834-16839.

Campbell DB, D’Oronzio R, Garbett K, Ebert PJ, Mirnics K, Levitt P, Persico AM (2007) Disruption of cerebral cortex MET signaling in autism spectrum disorder. Ann Neurol 62:243-250.

Campbell DB, Buie TM, Winter H, Bauman M, Sutcliffe JS, Perrin JM, Levitt P (2009) Distinct genetic risk based on association of MET in families with co-occurring autism and gastrointestinal conditions. Pediatrics 123:1018-1024.

Campbell DB, Warren D, Sutcliffe JS, Lee EB, Levitt P (2010) Association of MET with social and communication phenotypes in individuals with autism spectrum disorder. Am J Med Genet B Neuropsychiatr Genet 153B: $438-446$

Caviness VS Jr (1975) Architectonic map of neocortex of the normal mouse. J Comp Neurol 164:247-263.

Chao HT, Zoghbi HY, Rosenmund C (2007) MeCP2 controls excitatory synaptic strength by regulating glutamatergic synapse number. Neuron 56:58-65.

Courchesne E, Pierce K (2005) Why the frontal cortex in autism might be talking only to itself: local over-connectivity but long-distance disconnection. Curr Opin Neurobiol 15:225-230.

Dani VS, Nelson SB (2009) Intact long-term potentiation but reduced connectivity between neocortical layer 5 pyramidal neurons in a mouse model of Rett syndrome. J Neurosci 29:11263-11270.

Dani VS, Chang Q, Maffei A, Turrigiano GG, Jaenisch R, Nelson SB (2005) Reduced cortical activity due to a shift in the balance between excitation and inhibition in a mouse model of Rett Syndrome. Proc Natl Acad Sci U S A 102:12560-12565.

Ehninger D, Li W, Fox K, Stryker MP, Silva AJ (2008) Reversing neurodevelopmental disorders in adults. Neuron 60:950-960.

Frith C (2004) Is autism a disconnection disorder? Lancet Neurol 3:577.

Geschwind DH, Levitt P (2007) Autism spectrum disorders: developmental disconnection syndromes. Curr Opin Neurobiol 17:103-111.

Gibson JR, Bartley AF, Hays SA, Huber KM (2008) Imbalance of neocortical excitation and inhibition and altered UP states reflect network hyperexcitability in the mouse model of fragile X syndrome. J Neurophysiol 100:2615-2626.

Gogolla N, Leblanc JJ, Quast KB, Sudhof T, Fagiolini M, Hensch TK (2009) Common circuit defect of excitatory-inhibitory balance in mouse models of autism. J Neurodev Disord 1:172-181.

Gorski JA, Talley T, Qiu M, Puelles L, Rubenstein JL, Jones KR (2002) Cor- tical excitatory neurons and glia, but not GABAergic neurons, are produced in the Emx1-expressing lineage. J Neurosci 22:6309-6314.

Gutierrez H, Dolcet X, Tolcos M, Davies A (2004) HGF regulates the development of cortical pyramidal dendrites. Development 131:3717-3726.

Hallett M, Lebiedowska MK, Thomas SL, Stanhope SJ, Denckla MB, Rumsey J (1993) Locomotion of autistic adults. Arch Neurol 50:1304-1308.

Haswell CC, Izawa J, Dowell LR, Mostofsky SH, Shadmehr R (2009) Representation of internal models of action in the autistic brain. Nat Neurosci 12:970-972.

Hattox AM, Nelson SB (2007) Layer V neurons in mouse cortex projecting to different targets have distinct physiological properties. J Neurophysiol 98:3330-3340.

Haznedar MM, Buchsbaum MS, Hazlett EA, LiCalzi EM, Cartwright C, Hollander E (2006) Volumetric analysis and three-dimensional glucose metabolic mapping of the striatum and thalamus in patients with autism spectrum disorders. Am J Psychiatry 163:1252-1263.

Iarocci G, McDonald J (2006) Sensory integration and the perceptual experience of persons with autism. J Autism Dev Disord 36:77-90.

Jackson PB, Boccuto L, Skinner C, Collins JS, Neri G, Gurrieri F, Schwartz CE (2009) Further evidence that the rs $1858830 \mathrm{C}$ variant in the promoter region of the MET gene is associated with autistic disorder. Autism Res 2:232-236.

Judson MC, Bergman MY, Campbell DB, Eagleson KL, Levitt P (2009) Dynamic gene and protein expression patterns of the autism-associated met receptor tyrosine kinase in the developing mouse forebrain. J Comp Neurol 513:511-531.

Judson MC, Eagleson KL, Wang L, Levitt P (2010) Evidence of cellnonautonomous changes in dendrite and dendritic spine morphology in the met-signaling-deficient mouse forebrain. J Comp Neurol 518:4463-4478

Judson MC, Amaral DG, Levitt P (2011) Conserved subcortical and divergent cortical of proteins encoded by orthologs of the autism risk gene MET. Cereb Cortex, in press.

Just MA, Cherkassky VL, Keller TA, Minshew NJ (2004) Cortical activation and synchronization during sentence comprehension in high-functioning autism: evidence of underconnectivity. Brain 127:1811-1821.

Just MA, Cherkassky VL, Keller TA, Kana RK, Minshew NJ (2007) Functional and anatomical cortical underconnectivity in autism: evidence from an FMRI study of an executive function task and corpus callosum morphometry. Cereb Cortex 17:951-961.

Katz LC, Dalva MB (1994) Scanning laser photostimulation: a new approach for analyzing brain circuits. J Neurosci Methods 54:205-218.

Lefort S, Tomm C, Floyd Sarria JC, Petersen CC (2009) The excitatory neuronal network of the $\mathrm{C} 2$ barrel column in mouse primary somatosensory cortex. Neuron 61:301-316.

Levitt P, Eagleson KL, Powell EM (2004) Regulation of neocortical interneuron development and the implications for neurodevelopmental disorders. Trends Neurosci 27:400-406

Maina F, Hilton MC, Andres R, Wyatt S, Klein R, Davies AM (1998) Multiple roles for hepatocyte growth factor in sympathetic neuron development. Neuron 20:835-846.

Markram H, Rinaldi T, Markram K (2007) The intense world syndrome-an alternative hypothesis for autism. Front Neurosci 1:77-96.

Markram K, Markram H (2010) The intense world theory-a unifying theory of the neurobiology of autism. Front Hum Neurosci 4:224.

Marshall CR, Noor A, Vincent JB, Lionel AC, Feuk L, Skaug J, Shago M, Moessner R, Pinto D, Ren Y, Thiruvahindrapduram B, Fiebig A, Schreiber S, Friedman J, Ketelaars CE, Vos YJ, Ficicioglu C, Kirkpatrick S, Nicolson $\mathrm{R}$, Sloman L, et al. (2008) Structural variation of chromosomes in autism spectrum disorder. Am J Hum Genet 82:477-488.

Micheva KD, Beaulieu C (1996) Quantitative aspects of synaptogenesis in the rat barrel field cortex with special reference to GABA circuitry. J Comp Neurol 373:340-354.

Milutinovic S, D'Alessio AC, Detich N, Szyf M (2007) Valproate induces widespread epigenetic reprogramming which involves demethylation of specific genes. Carcinogenesis 28:560-571.

Morishima M, Kawaguchi Y (2006) Recurrent connection patterns of corticostriatal pyramidal cells in frontal cortex. J Neurosci 26:4394-4405.

Mostofsky SH, Powell SK, Simmonds DJ, Goldberg MC, Caffo B, Pekar JJ (2009) Decreased connectivity and cerebellar activity in autism during motor task performance. Brain 132:2413-2425. 
Moy SS, Nadler JJ (2008) Advances in behavioral genetics: mouse models of autism. Mol Psychiatry 13:4-26.

Neymotin SA, Jacobs KM, Fenton AA, Lytton WW (2010) Synaptic information transfer in computer models of neocortical columns. J Comput Neurosci 30:69-84.

Otsuka T, Kawaguchi Y (2008) Firing-pattern-dependent specificity of cortical excitatory feed-forward subnetworks. J Neurosci 28:11186-11195.

Persico AM, Bourgeron T (2006) Searching for ways out of the autism maze: genetic, epigenetic and environmental clues. Trends Neurosci 29:349-358.

Pfeiffer BE, Huber KM (2009) The state of synapses in fragile X syndrome. Neuroscientist 15:549-567.

Pinto D, Pagnamenta AT, Klei L, Anney R, Merico D, Regan R, Conroy J, Magalhaes TR, Correia C, Abrahams BS, Almeida J, Bacchelli E, Bader GD, Bailey AJ, Baird G, Battaglia A, Berney T, Bolshakova N, Bölte S, Bolton PF, et al. (2010) Functional impact of global rare copy number variation in autism spectrum disorders. Nature 466:368-372.

Rasalam AD, Hailey H, Williams JH, Moore SJ, Turnpenny PD, Lloyd DJ, Dean JC (2005) Characteristics of fetal anticonvulsant syndrome associated autistic disorder. Dev Med Child Neurol 47:551-555.

Rinaldi T, Silberberg G, Markram H (2008a) Hyperconnectivity of local neocortical microcircuitry induced by prenatal exposure to valproic acid. Cereb Cortex 18:763-770.

Rinaldi T, Perrodin C, Markram H (2008b) Hyper-connectivity and hyperplasticity in the medial prefrontal cortex in the valproic acid animal model of autism. Front Neural Circuits 2:4.

Rubenstein JL, Merzenich MM (2003) Model of autism: increased ratio of excitation/inhibition in key neural systems. Genes Brain Behav 2: 255-267.

Scott-Van Zeeland AA, Abrahams BS, Alvarez-Retuerto AI, Sonnenblick LI, Rudie JD, Ghahremani D, Mumford JA, Poldrack RA, Dapretto M, Geschwind DH, Bookheimer SY (2010) Altered functional connectivity in frontal lobe circuits is associated with variation in the autism risk gene CNTNAP2. Sci Transl Med 2:56ra80.

Shepherd GMG (2009) Intracortical cartography in an agranular area. Front Neurosci 3:337-343.

Shepherd GMG (2011) Circuit mapping by ultraviolet uncaging of glutamate. In: Imaging in neuroscience: a laboratory manual (Helmchen F, Konnerth A, Yuste R, eds), pp 417-427. Cold Spring Harbor, NY: Cold Spring Harbor Laboratory.

Shepherd GMG, Pologruto TA, Svoboda K (2003) Circuit analysis of experience-dependent plasticity in the developing rat barrel cortex. Neuron 38:277-289.

Shepherd GMG, Stepanyants A, Bureau I, Chklovskii DB, Svoboda K (2005) Geometric and functional organization of cortical circuits. Nat Neurosci 8:782-790.

Sousa I, Clark TG, Toma C, Kobayashi K, Choma M, Holt R, Sykes NH, Lamb JA, Bailey AJ, Battaglia A, Maestrini E, Monaco AP (2009) MET and autism susceptibility: family and case-control studies. Eur J Hum Genet 17:749-758.

Sudhof TC (2008) Neuroligins and neurexins link synaptic function to cognitive disease. Nature 455:903-911.

Suter BA, O'Connor T, Iyer V, Petreanu LT, Hooks BM, Kiritani T, Svoboda K, Shepherd GMG (2010) Ephus: multipurpose data acquisition software for neuroscience experiments. Front Neurosci Methods 4:1-12.

Teitelbaum P, Teitelbaum O, Nye J, Fryman J, Maurer RG (1998) Movement analysis in infancy may be useful for early diagnosis of autism. Proc Natl Acad Sci U S A 95:13982-13987.

Tennant KA, Adkins DL, Donlan NA, Asay AL, Thomas N, Kleim JA, Jones TA (2010) The organization of the forelimb representation of the C57BL/6 mouse motor cortex as defined by intracortical microstimulation and cytoarchitecture. Cereb Cortex 21:865-876.

Thanseem I, Nakamura K, Miyachi T, Toyota T, Yamada S, Tsujii M, Tsuchiya KJ, Anitha A, Iwayama Y, Yamada K, Hattori E, Matsuzaki H, Matsumoto K, Iwata Y, Suzuki K, Suda S, Kawai M, Sugihara G, Takebayashi K, Takei N, et al. (2010) Further evidence for the role of MET in autism susceptibility. Neurosci Res 68:137-141.

Van De Werd HJ, Rajkowska G, Evers P, Uylings HB (2010) Cytoarchitectonic and chemoarchitectonic characterization of the prefrontal cortical areas in the mouse. Brain Struct Funct 214:339-353.

Weiler N, Wood L, Yu J, Solla SA, Shepherd GMG (2008) Top-down laminar organization of the excitatory network in motor cortex. Nat Neurosci 11:360-366.

Wood L, Shepherd GM (2010) Synaptic circuit abnormalities of motorfrontal layer $2 / 3$ pyramidal neurons in a mutant mouse model of Rett syndrome. Neurobiol Dis 38:281-287.

Wood L, Gray NW, Zhou Z, Greenberg ME, Shepherd GM (2009) Synaptic circuit abnormalities of motor-frontal layer $2 / 3$ pyramidal neurons in an RNA interference model of methyl-CpG-binding protein 2 deficiency. J Neurosci 29:12440-12448.

Zoghbi HY (2003) Postnatal neurodevelopmental disorders: meeting at the synapse? Science 302:826-830. 